\title{
LEGACY OF FOLK PAINTINGS IN ASSAM
}

\section{BIKASH DAS}

Research Scholar,Department of MIL \& LS, Gauhati University, Guwahati, Assam, India

\begin{abstract}
The royal ancestry of ancient Assam had aculture of rejoicing inliterature. The Sanchi Puthis were thus created to preserve this heritage from the ongoing process. Other than Sanchi leaves, Tula leaves were also used to write texts on. And the Sanchi Leaves and Tula leaves were also used, to be drawn or painted on. The majority of these texts are in ruins. However, the ones that still existare kept and preserved in various institutions. These texts have carried forward the folk impression of the culture and heritage of Assam. The paper that goes by the name of Legacy of Folk Paintings in Assam has descriptive discussions about the manuscript paintings.
\end{abstract}

KEYWORDS: Assam, Change, Culture, Folk, Paintings

Received: Oct 02, 2020; Accepted: Oct 22, 2020; Published: Nov 05, 2020; Paper Id.: IJESROCT20201

\section{INTRODUCTION}

The Painting culture of Assam may be considered archaic. The epic Mahabharata has mentions of the Demon-king Baan's daughter, Usha's acquaintance to hold expertise in the art of painting. Following the boon from Goddess Parvati, Usha dreams of the Divine Prince, Aniruddha Dev, and Chitralekha, upon being insisted by her friend, paints all the heroic warriors of the three worlds: Human, Demon, Gandharva, Kinnar and Yadava clan along with Aniruddha Dev, eventually enabling the princess to find her match.

The King of the ancient kingdom of Kamrup, Kumar Bhaskar Barma, is believed to have sent a some token of gifts that also included an album of various vibrant paintings depicting the culture of Kamrup to the then Emperor of India, Harshavardhana, in order to establish affinity. The successors of Bhaskar Barma are believed to have depiction of the royal courts in copper sheets and encouraged the idea of decorating the walls of the palaces and courts with paintings. The following Shalstambha or the Paal Dynasty had monarchs who incentivized the idea of painting the walls of halls and temples built for public socio-religious uses.

The medieval period holds history of the prominent artist, Srimanta Sankardeva who in order to build the Imagery-Procession drew seven images of the Vaikuntha to reach out to the commons and capture their attention towards the Vaishnav culture through Episodic Dramas. This Great Artist-visionary had gifted the Koch King Naranarayana with theBrindabaniVastra, which in contemporary periods is regarded to be a primordial element of culture and heritage of Assam.

\subsection{Discussion}

Notably around four hundred years ago, handful of people exterior the state is conscious of Assam has an adequately rich heritage of painting substantiated by the size able number of ancient illuminated manuscripts pervasive the state. A few of these manuscripts such as the Chitra-bhagavata and the Hastavidyarnava have been 
bring to public notice in book form with replication of the paintings and they have highlighted the attentiveness of the art lovers and specialists. Gleaned from accessible manuscript paintings of this area, specific study was carried out by scholars like Dr. Maheswar Neog and Dr.Rajatananda Dasgupta. The technique and implementation of the paintings of the manuscripts like the two named on the top are sophistically redundant and filtered for the works to be categorized as folk paintings, but somewhere there is absence of some folk elements. Although there are other spot lighted manuscripts where the paintings are still less sophisticated and disclose a prominent degree of folk interrelation. Thereupon, past aged times powerful indications existed in Assam, surpassing one style of the folk painting- determined from the various styles of the manuscripts paintings which must have born out of previous folk styles.

Repeated mentioning of paintings known as pats and group of painters termed as patuas were noticed in the middle aged Assamese Literature. Nevertheless, patuas are not noticed in Assam now. In the Kamrupi accent of Assamese, there is a style still prevailing which indicates to the use of painting correlated to another community, the nats or professional singers and dancers. The style natather pat defines a painting of the shack of the nats. In current times, nats as a professional class also don’t survive in Assam.

Khanikars who were versatile class of artists' people - not a caste, begin diverse artistic work for instance woodcarving, painting, image- making, costume - designing, stage - set- making, and make-up for theatricals and so forth. Once they obtained court patronage and were arranged somewhat into guilds (Assamese Khel). The Khanikars experienced long lasting encouragement from the neo- Vaishnava artistic effervescence, also the amount of tasks done by the Khanikars have ring- shaped the satras (monasteries ) and nam-ghars (prayer halls). In Upper Assam, few skilful Khanikars can be still found in present day; yet disclosed previously, the Khanikars aren't trained in painting. Execution of paintings is done to enhance the carved panels, masks, votive structures or pedestals, book- stands, and so forth. A little self- reliance painting is done on a flat exterior.

Excluding the aforesaid distinct form, in utmost parts of Assam today the local traditions of folk paintings are close to death. Favourably, in the Lower Assam regions of Kamrup and Goalpara (undivided) precisely in the latter a tradition of folk painting still breathes more or less. The middle state of the painting -layers of pith or the Indian cork- is very uncommon. Some tasks on pith are done in other parts of Indian sub- continent. The pith artists in general don't build different large articles incorporating paintings which are so deeply linked with the local folk life. According to the viewpoint of Dr. Verrier Elwin the genesis of the work on pith is in this region where reed sprouts sufficiently in marshland; and it was the mastermind of the local artisans that placed the local material into righteous utilization. The caste termed Mali or Malakar in Assam as well as the caste of west Goalpara region are generally related with the making of pith articles can be acknowledged here, whereas the craft in Assam is not widely used by members of this caste. People from different castes can do take up the craft. Also in some areas all the pith workers reside from other castes.

Generally, a major portion of the pith articles made by the Malis have been largely interconnected with the beliefs and religions of local folk. A large number of depiction of Gods and God lings of the resident pantheon additionally toys and headgears were built in some portion of west Goalpara. Amid ritualistic articles, images and other articles linked with the local Manasa cult (Mare/ Marai) noticeable in number and variation. Malis, in areas where they are functioning either they make images and toys pith or not they make interim dedicated forms of pith on which they give rise to amusing traditional paintings. Called by various names like maju, manjush, mandisha and tepari (the name differs from place to place), these structures vary greatly in height, size and the paintings imprinted on them exhibit various local styles. The 
themes illustrated in the pictures are mostly involved with the local Manasa cult, also drawn from the famous Beula legend. The primary themes represented in these paintings are Brahma, Siva, Manasa, the merchant Chando on his boat, the floating rift with Beula and her dead husband, etc. Paintings which don't constitute portion of dedicated structures but are made differently and wholly are defined as pats. The majority of them are Bishohori pats, Bishohari a famous form of Manasa.

It is noticed that community effort of pith artists' work prevails more or less on the north bank of Brahmaputra in the Goalpara region. Even - though independent artistic skill and brilliance do add up, the products are hugely stylized. The artists who belong from the Rabha tribal community and some to the Ganak (astrologer ) class found in the south bank, their art is less standardized and is of less community affair; the artistic attempts is more or less of an independent imprint. Traditionally, the application of painting on pith is carried out from ages; the art form alone is not too standardized.

The folk artists in various areas restricted themselves to materials, themes and styles that were essentially recited by the local tradition which is beyond question. Indeed individual artists had move out from this traditional region. For instance, based on themes drawn from the epics and Puranas pats or paintings were created. Likewise, artists who were part of the Rabha tribal community, where drinking rice beer is a part of social activities, portray a drinking scene. The scenes illustrated centralizing the myths of the local Manasa cult - largely famous in the Lower Assam region, represents the popular folk entertainment institutions.

During recent times, owning to numerous parameters like variations in the socio- economic condition, the downfall of the grasp of the traditional folk beliefs on the village population and the extension of mass culture, many notable transformations in the paintings emerged out by the pith painters have been taken place. The most common alteration has been in the usage of materials. As there is scarcity of pith and it is becoming costly too; further due to the negligence from the devotees or the artists about the rightness of the traditional paraphernalia- the usage of white paper become common instead of pith sheets. Sometimes the use of typical newspaper sheets is seen. Switch from locally made colours to bazar colours has been substantially raised, accessible data points out that it has occurred in the field of folk painting nearly all over India.

Redesign in the themes is also seen. In addition to the occasionally build paintings with themes from epics etc., recently pith workers have taken to make non - traditional articles like portrayal of Saraswati and Durga and new- fangled 'stylish' toys. Significant changes are seen in the traditional colour schemes along with variations in range of production.

Several noteworthy changes have taken place in the area of flat- surface painting also. We can cite some fascinating instances.

In years gone by, a renowned present - time commercial artist hails from the Gauripur area of Goalpara determined to employ folk paintings to display the idea of space in an exhibition giving attention to travel space. The representation of the nine planets (navagraha) which when positioned side by side, would represent the idea of space were executed by some pith artists. Traditionally, the pith artists had not been doing navagraha paintings. With the utilization of traditional methods and styles, they build astonishing paintings depicting the nine planets only when they were explained the traits, features of the grahas along with some commencing recommendation. In spite of the fact that the navagraha idea is not so firmly connected with the traditional folk beliefs and customs of the area, certain pith artists are now tirelessly 
furnishing the navagraha series as they discover it has a better commercial market supported by some Government agencies.

Two more examples are cited below which tells the change of tradition in paintings done on majus. These are the instances from South Goalpara.

It is already mentioned that in the traditional maju paintings of this area there had been some independent privilege to divert from the traditional ritualistic themes. Further discussion about the drinking scene is explained in detail. Two remarkable changes have been noticed in recent years in majus produced. Firstly, materials are identical, the usage of brush and colour act in accordance nearly with the traditional styles, but the traditional themes are absent. In lieu of Gods and Goddesses and scenes from the Beula legend, mostly there are boys and girls dressed in trousers and frocks, and all. Also the two boats which have been drawn, possibly as a modification to tradition, don't seem to display a scene from the famous legend.

Secondly, we observe that the themes are highly traditional- Gods and Goddesses linked with the local Manasa cult and scenes from the legend, etc. all are present; but the materials are dissimilar. Instead of pith sheets we have paper, alternatively for bazar colours that have been nearly adjusted to this traditional art style; we have usage of enamel paint. Most importantly there is less involvement with the traditional style in most of the pictures. Most of them carry the spot of the effect of the calendar art.

The pair changes resemblance the effect of mass culture on folk culture; the first focus on change in the way of life of people and the next highlight the change in the point of view of artists themselves.

\subsection{Acknowledgement}

We have to thank all the authors who previously researched and studied about folk paintings of Assam. Without them it would not have been possible to carry forward this study. This study has no financial implication or assistants and it is only done to know about the legacy of folk painting in Assam.

\section{CONCLUSIONS}

Folk paintings are the most precious resources and asset of Assam. In contrast to other parts of India, Assam's folk paintings were of high standards. Ancient Assam's painters were also very hardworking and dedicated to their work. The equipment required to draw and complete a painting were made by the painters with utmost diligent. However in the contemporary times due to the effects of modernization and globalization, Assam's exceptional folk paintings are fading away. Apart from few painters others have diverted their prime interest from authentic style of local paintings to western style of painting. In the present times as the interest in folk paintings are fading out and making them lose strength it's high time these folk paintings are conserved, study and research should be done on them and it must be taken seriously before it loses its identity and get extinct.

\section{REFERENCES}

1. Datta, B. 1994. Folk paintings in Assam, Guwahati: Directorate of Cultural Affairs.

2. Dutta, B, Sarma, N.K. \& Das, P.C. (ed.) 1994. A handbook of folklore Material of North east India, Published by ABILAC

3. Gogoi, L. 1994, Asamar samskriti. Banalata prakashan. 
4. SODHI, S., N. ARYA, and N. YADAV. "ASSESSMENT OF ADAPTED MOTIFS OF MADHUBANI PAINTING." International Journal of Agricultural Science and Research (IJASR) 6.2, Apr 2016, 245-250

5. Neog, M. 2008. Asamiya Sahityar Ruprekha, Chandra Prakash.

6. Neog, m. 1984. Religions of the North-East. New Delhi. Munshiram Manoharlal Publishers pvt. Ltd.

7. Sarma, S.n. 2006. Asamiya sahityar itibritta. Soumar Prakash, Guwahati

8. Savithri, G., P. Sujathamma, and C. H. Ramanamma. "Glory of Indian Traditional Silk Sarees." International Journal of Textile and Fashion Technology (IJTFT0 3.2 (2013): 61-68.

9. Sarma Doloi, H. 1965. Sahitya aru Samskriti, Barpeta

10. NSAIDZEDZE, IGNATIUS. "WOMEN AND NATIONALISTIC POLITICS IN ROBERT BROWNING'S POETRY: A FEMINIST READING OF 'BALAUSTION'S ADVENTURE AND 'ARISTOPHANES APOLOGY." International Journal of English and Literature (IJEL) 7.4, Aug 2017, 43-64

11. Vatsyayana, Kapila, 1981. A Study of Performing Arts in Eastern India. Guwahati: Gauhati University.

12. SODHI, S., N. ARYA, and N. YADAV. "CREATION OF DESIGNS BY ADAPTATION OF MADHUBANI PAINTING MOTIFS." International Journal of Humanities and Social Sciences (IJHSS) 5.5, Aug - Sep 2016; 89-94 

